\title{
Injuries of the spine sustained in rugby
}

\author{
J R SILVER
}

\begin{abstract}
Between 1952 and 1982, 67 rugby players (63 rugby union, two rugby league, and two American football) sustained serious injuries of their spine. The injuries fell predominantly on the lower cervical spine. Forty eight of the players sustained serious injuries of the spinal cord, leading to paralysis and total incapacity. The incidence of such injuries appears to have increased in recent years, particularly those incurred in tackles and mauls and rucks, and particularly among schoolboys. Changes in the laws of the game and in the attitudes of the players over the past few years should improve play and lead to a lower incidence of injuries.
\end{abstract}

\section{Introduction}

Injuries are an inevitable consequence of any game that entails body contact. Sparks compared the incidence of injury in rugby football with the incidences in other sporting activities undertaken at Rugby School over the past 30 years and found the incidence of injuries in rugby (198 cases/10 000 hours) to be nearly double that of the sport with the next highest incidence-namely, basketball (103 cases/10 000 hours). ${ }^{1}$ By far the most common injury was concussion (513 cases). Five spinal injuries occurred, four of which were to the cervical spine, but none gave rise to paralysis. Similar surveys carried out among

This material has been presented at many scientific, meetings over the past 12 years, the most important of which were the joint meeting of British and Belgian neurologists in Brussels, 20-22 May 1976, and the seventh annual conference for staff and senior coaches of the Rugby Football Union, Bisham Abbey, 14-16 May 1982.

National Spinal Injuries Centre, Stole Mandeville Hospital, Aylesbury, Bucks HP21 8AL

J R SILVER, FRCP, FRCPED, consultant in spinal injuries rugby players found similar proportions of head and neck injuries. ${ }^{2} 3$

Although numerically few, serious injuries of the spine that give rise to paralysis have attracted considerable attention over the past few years. ${ }^{4-8}$ I have been studying the cause, incidence, and possible means of preventing such injuries since 1972 and have obtained details of 67 players injured over this period, some of whom have been reported on previously. ${ }^{9-11}$ In this paper I present these details, analyse the factors causing injury and the mechanisms of injury, and discuss recommendations that have been made to the Rugby Football Union in an effort to prevent such injuries.

\section{Anatomical factors and mechanics of injury}

Injuries to the thoracic and lumbar vertebrae from knocks, kicks, or blows during a game do not give rise to damage to the spinal cord or roots, but the cervical cord is particularly vulnerable to injury. The thoracic and lumbar spines are protected by thick muscles and large sturdy vertebrae; they are splinted by the ribs and pelvis and are relatively immobile. The cervical spine is much more mobile. The likelihood of damage occurring to the cervical vertebrae is enhanced by the disparity in the movements of the unsupported skull on the cervical spine. The skull may be likened to a heavy ball on the end of a chain. The force created by movement will fall on the two vulnerable junctions of the skull and cervical spine and the relatively mobile cervical spine and fixed thoracic spine. The danger of dislocation occurring is further increased by the alignment of the facets, which in the upper cervical spine do not present such resistance to dislocation as the vertebrae lower down because their facets are aligned less obliquely.

Flexion-When a force is exerted through the crown of the head it is transmitted through the skull to the cervical vertebrae, resulting in crushing of the vertebrae and extrusion of the vertebral body and disc material posteriorly into the cervical cord. Dislocation may occur without any fracture of the vertebrae. Roaf, using cadaveric spines, was unable to produce dislocation without a fracture by hyperflexion alone and found that some rotation must be present. ${ }^{12}$ Bauze and Ardran solved this problem by showing that when the 


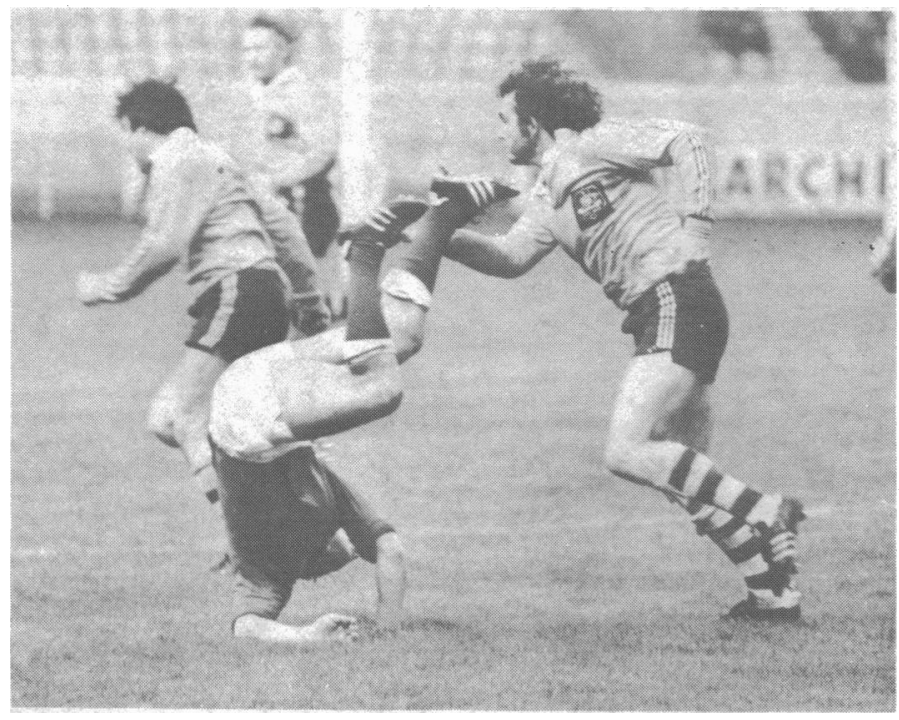

FIG 1 -Blows to the head are common in rugby union football. The force generated by such a blow is sufficient to fracture or dislocate the spine.

vertex is fixed (being locked on the ground, a common occurrence in rugby) (fig 1) far less force is required to dislocate the vertebra and dislocation can occur without fracture. ${ }^{13}$

Spearing-A blow to the head may not be transmitted to the spine but may be absorbed by the brain and result in instantaneous respiratory and cardiac arrest.

Extension-The anterior posterior diameter of the spinal cord is reduced during extension of the cervical spine so that when the neck is forcibly extended the spinal cord is compressed between the discs and vertebral bodies anteriorly and the lamina and ligaments posteriorly. The cord can thus be injured without there being any overt fracture or dislocation-the so called "extension" injury.

Blow to the neck (as in short arm tackles)-A blow to the neck over the carotid artery results in transient spasm of the vessel and unconsciousness without any bony injury.

\section{Injuries and how they were sustained}

Between 1952 and 1982 I studied 67 patients with serious spinal injuries sustained in games of rugby; most of these patients I treated personally at the Liverpool Regional Paraplegic Centre (1965-70) and the National Spinal Injuries Centre (1970-82), though a few case histories were sent to me from Oswestry and the north of England. Most of the patients had sustained serious injuries to the spinal cord-four died as a result-but in a few cases the injuries were less severe. Of the 67 players injured, 63 were playing rugby union football, two rugby league football, and two American football. The 63 players injured in rugby union football sustained 64 injuries. Six players were of first class standard, 33 were of club standard, 16 played in schoolboy teams, and four played in other schoolboy games; in five cases the player's standard was not known. Of the 67 games in which injuries were sustained, three were of first class standard, 34 were club games, 12 were school team games, four were other school games, and three were practice games; in 11 cases the standard of the game was not known or not relevant.

\section{NEUROLOGICAL CONDITION}

Among the 63 players injured while playing rugby union football 48 had cord injuries leading to paralysis (complete in 21 , incomplete in 27). Four patients had root injuries that were also severe and led to incapacity and time off work; at least three patients had to undergo spinal fusions or laminectomies subsequently. In three cases the neurological condition was not known. Seven patients did not have cord injuries but were referred to me because of my interest in rugby injuries. The remaining patient was a hysteric.

Level of cord injuries-The cord injuries were predominantly at the level of the fourth to seventh cervical segments, which is in keeping with findings in large series of spinal injuries sustained in road traffic accidents (table I). Only one patient had a T8 lesion; this was the result of a fall down stairs at 4 am when he was drunk.

Level of vertebral injuries-Again, most of the injuries affected the lower cervical vertebrae (table II); this is similar to the experience of Braakman and Penning in other traumatic injuries of the cervical spine. ${ }^{14}$ Possibly this is a self selecting series as patients with injuries of the odontoid peg have either no neurological injury or a fatal injury. Most (41) of the patients had flexion injuries; six had extension injuries, and in 21 cases the mechanism of injury was unknown. One patient sustained two separate injuries, one flexion and one extension.

TABLE I-Level of transection of cord

\begin{tabular}{lcc}
\hline & Complete & Incomplete \\
\hline C1 & & \\
C2 & 1 & 1 \\
C3 & 6 & 7 \\
C4 & 4 & 3 \\
C5 & 6 & 2 \\
C6 & 1 & 1 \\
C8 & 2 & \\
T8 & 1 & 27 \\
\hline Total & 21 & \\
\hline
\end{tabular}

TABLE II-Level of vertebral injuries in all 67 players*

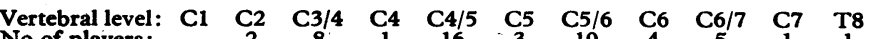

* Two players had injuries to the cervical vertebrae but the exact level was not known in one player the vertebral level was completely unknown; and four players did not have a bone injury. One player was injured twice at the same vertebral level; he is included only once.

\section{PLAYERS' POSITION IN GAME}

On some occasions the player was injured while playing out of position (table III).

TABLE III-Analysis of players' positions and mode of injury*

\begin{tabular}{|c|c|c|c|c|c|c|c|}
\hline \multirow[b]{2}{*}{. } & \multicolumn{2}{|c|}{ Tackle: } & \multirow{2}{*}{$\begin{array}{c}\text { Tackle, } \\
\text { but } \\
\text { details } \\
\text { not known }\end{array}$} & \multirow[b]{2}{*}{ Scrum } & \multirow{2}{*}{$\begin{array}{c}\text { Ruck/ } \\
\text { maul }\end{array}$} & \multirow[b]{2}{*}{ Blow } & \multirow{2}{*}{$\begin{array}{c}\text { Running } \\
\text { and } \\
\text { tripped }\end{array}$} \\
\hline & $\begin{array}{c}\text { Ball } \\
\text { carrier }\end{array}$ & Tackler & & & & & \\
\hline $\begin{array}{l}\text { Rugby union: } \\
\text { Forwards } \\
\text { Backs } \\
\text { Not knownt }\end{array}$ & $\begin{array}{l}3 \\
9\end{array}$ & $\begin{array}{l}4 \\
6\end{array}$ & 1 & 13 & $\begin{array}{r}14 \\
4 \\
2\end{array}$ & 2 & 1 \\
\hline $\begin{array}{l}\text { Rugby league } \\
\text { American }\end{array}$ & 1 & & & 1 & & & \\
\hline $\begin{array}{l}\text { football } \\
\text { Hysteria }\end{array}$ & 1 & 1 & & 1 & . & & \\
\hline
\end{tabular}

* One player was injured twice.

tThree additional players whose positions were irrelevant were injured: one was injured while exercising; one fell down stairs while drunk; and one was injured when someone jumped on his neck after a game.

Players injured in scrums-Fifteen players were injured in scrums (table III), 14 while playing rugby union and one while playing rugby league. Figure 2 shows how the injuries were sustained by 12 of the rugby union players. Of the three remaining players, two (one of whom had hysteria) were injured when the scrum collapsed; in the remaining case the mechanism of injury was not known. Only one player was a second row forward, which indicates the dangers of playing in the front row. A separate analysis of the distribution of injury between hookers and tight and loose head props was not made.

Three players were injured at the formation of the scrum as a result of extension or forced flexion of the neck. The remainder were injured when the front row collapsed (fig 3) and the second row continued to push; this fulfils the mechanisms required by Bauze and Ardran, ${ }^{13}$ which have been fully described elsewhere. ${ }^{4}$ Collapse of the scrum may be due to a discrepancy of strength and skill or may be deliberate. There does not appear to have been any change in the incidence of such injuries (fig 4).

Players injured while tackling-Four forwards, six backs, and one player whose position was unknown were injured while tackling. 


\section{FRONT ROW FORWARDS}

Horse play; scrum collapsed and second row kept pushing Scrum collapsed

Inexperienced opposition: scrum collapsed

Schoolboys $v$ adults

Got down late; powerful opposition

Slipped while playing against last year's first team

His prop was fighting the opposing prop. His prop left the scrum, which then collapsed

Head forced to one side by opposite prop's boring

Wearing training shoes and slipped

Incorrect packing down *

Scrums charged; had previously always played as a three quarter*

\section{SECOND ROW}

Could not bind to front row

FIG 2-Analysis of 12 injuries incurred by forwards in front row and a second row player in scrums.

* Player played as hooker in this game.

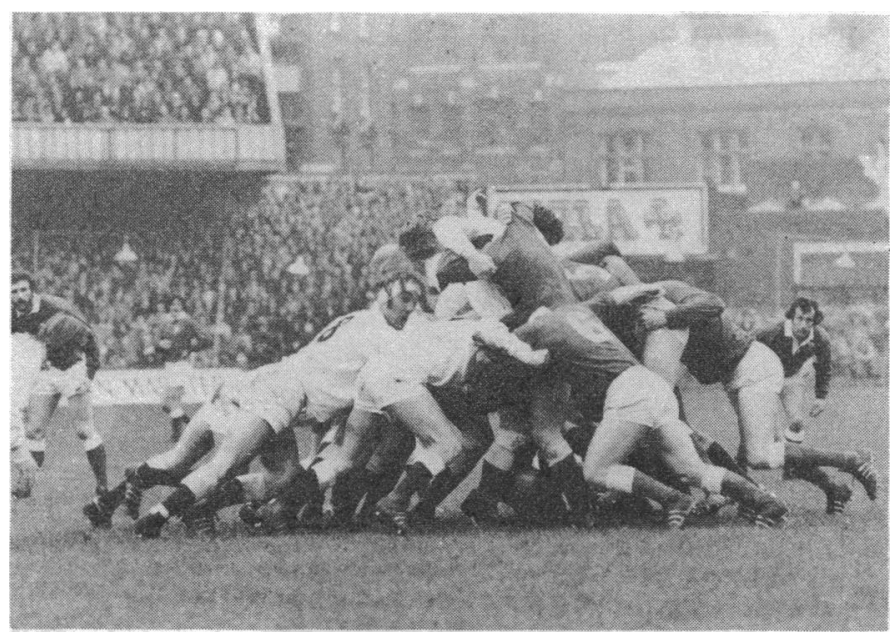

FG 3-The front rows of the scrum have been disrupted. Should the second rows continue to push then the front row players are at risk of having their heads driven into the ground.

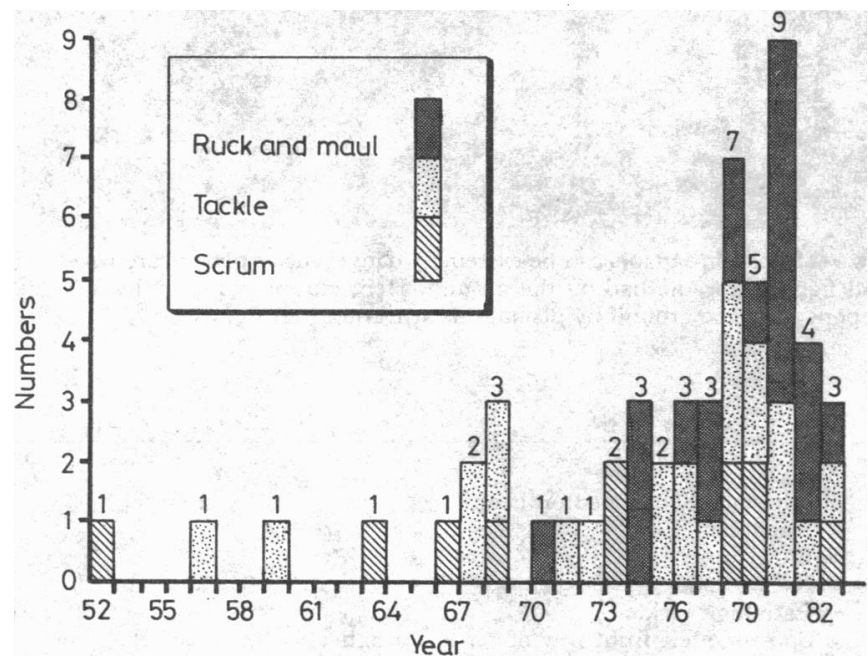

FIG 4-Numbers of injuries occurring in set scrums, tackles, and rucks and mauls in rugby union football by year (figures at top of each column indicate total number of such injuries each year). (Year not known for two injuries incurred in scrums and one in a tackle; the hysteric who was injured in a scrum is also omitted.)
Nine of the injuries were the result of mistimed crash tackles: either the head went in front of the thigh and was swept up by the thigh, or the head struck the body or limbs of the player carrying the ball, causing spearing or a crush fracture (fig 5). One player made a bad high tackle and his opponent injured him by falling on him. Figure 4 shows how the numbers of injuries incurred in tackles have increased in recent years.

Players injured in a tackle while carrying the ball-Fourteen players were injured when they were tackled while carrying the ball (fig 6); four of these tackles were illegal. An example of an illegal tackle was

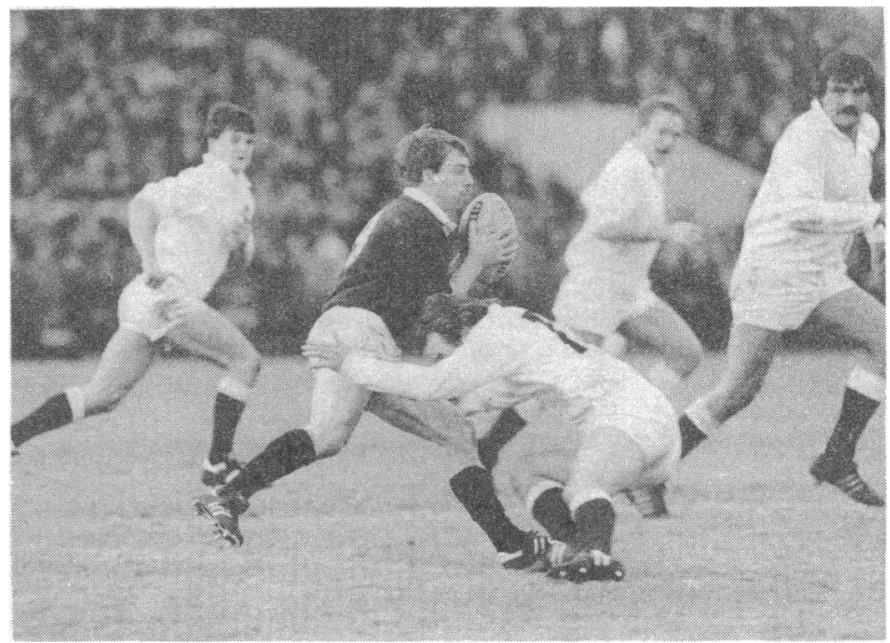

FIG 5-A dangerous tackle. The tackler's head and shoulders are in front of his opponent. The tackler's head may be injured by striking his opponent's body, or his jaw and neck may be injured as his opponent's thigh comes through, sweeping the head up.

RUGBY UNION
Blow on head
Strangled*
Tackled and two people fell on him
Pushed from behind; fell on top of his head
Thrown back on his head
Dropped on head
Flexion caused by three opponents
Late high tackle by two opponents
Tackled by three opponents
Fell badly when opponent attempted to tackle him
Speared himself on opponent
Short arm late tackle on him*
Illegal tackle* RUGBY LEAGUE
Clotheslined* amERICAN FOoTBALI

FIG 6-Analysis of 14 injuries incurred in tackles.

*Illegal tackles.

when a player was strangled by an opponent who broke his neck in a "friendly" match. Four players were injured as a result of a multiple tackle (fig 7); it was not clear in some cases whether the neck was broken in the tackle or in the ensuing pile up. Four players were injured when their heads struck the ground violently. One player speared himself.

Players injured in ruck and maul-Twenty players were injured in a ruck and maul (fig 8). Fifteen were forced to the ground and either their own side continued to push on their buttocks so that their heads were driven into the ground or players piled on top of them in an attempt to kill the ball (fig 9). One player described how he felt a 


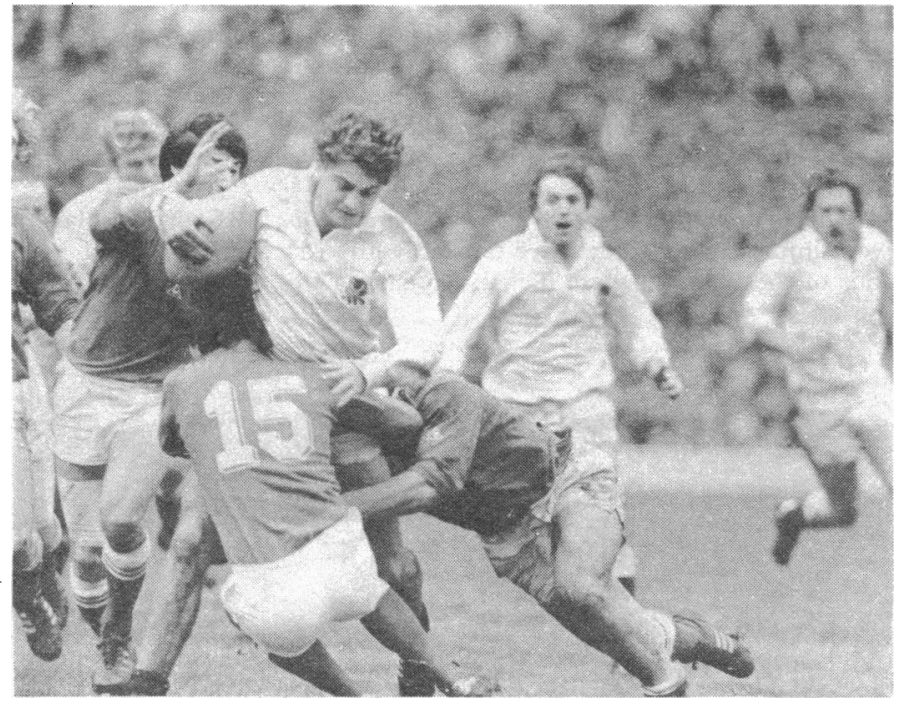

FIG 7-A potentially dangerous tackle. A player is tackled by three opponents simultaneously and is unable to move away from the tackle.

\section{THREE QUARTERS}

Forced himself down to score and suddenly collapsed Tackle: maul

Collapse ruck; fell awkwardly with other players on top Ruck; players formed on top of him

\section{FORWARDS}

Pushed down, head driven into ground

Kicked in back of neck in ruck

While trying to force ball back between his legs was forced to ground

Pushed from behind

Pushed from behind

Deliberately broken by strangle

Tried to force through

Forced into ground

Forced into ground

Forced into ground

Forced into ground, did somersault

Pushed ball back between legs, other players pushed in

Pushed from behind

Forced down

\section{POSITION NOT KNOWN}

Players piled in on top

Fell forward while picking up ball; other players piled in

FIG 8-Analysis of 20 injuries incurred in rucks and mauls.

click as his head struck the ground, followed by severe pain and paralysis as supporting forwards pushed on his buttocks, raising his hips. Two players injured themselves by trying to force their way through other players and striking their heads. One player was kicked and another deliberately strangled. More forwards than other players are injured in rucks and mauls because they are actively seeking out the ball there. The numbers of injuries incurred in rucks have increased strikingly recently, none having occurred before 1970 (fig 4).

\section{INJURIES DUE TO STUPIDITY}

Three players were injured as an indirect consequence of the game. One was injured when someone jumped on the back of his unguarded neck while he was resting on the ground; one, who was drunk, fell down stairs at 4 am while on tour; and one was tipped over someone's back in an exercise in which players' arms were linked, an exercise condemned by the Rugby Football Union in their coaching scheme booklet.

\section{EFFECT OF FITNESS}

General-Nine players were injured probably because they were not fit enough. Four players claimed that they were not generally fit to be playing any kind of sport. One was a patient with schizophrenia, who went straight from hospital to his local rugby club, asked for a game, and was immediately injured. One player turned up at his club before the season had started, not intending to play, and played in a practice game in an unfamiliar position (the front row) on a wet pitch in training shoes against the first team. Five players were injured in the first game of the season.

Specific-Three players were injured because they had not received sufficient specific training. A wing three quarter was made to play as a front row forward because of his strength and general ability but was unable to cope with the particular skills required; a schoolboy who had played only three or four games of rugby was put in the first team and was injured in a maul and ruck in a match between schools; and another player had played for only half a season.

\section{FOUL PLAY}

Eight players were injured as a result of foul play (fig 10; and see above).

\section{MISMATCH OF STRENGTH AND SKILI}

Some injuries occurred where there was a discrepancy of strength and skill, particularly in the front rows of the scrum. On four occasions there was a discrepancy of skills, and on seven occasions schoolboys

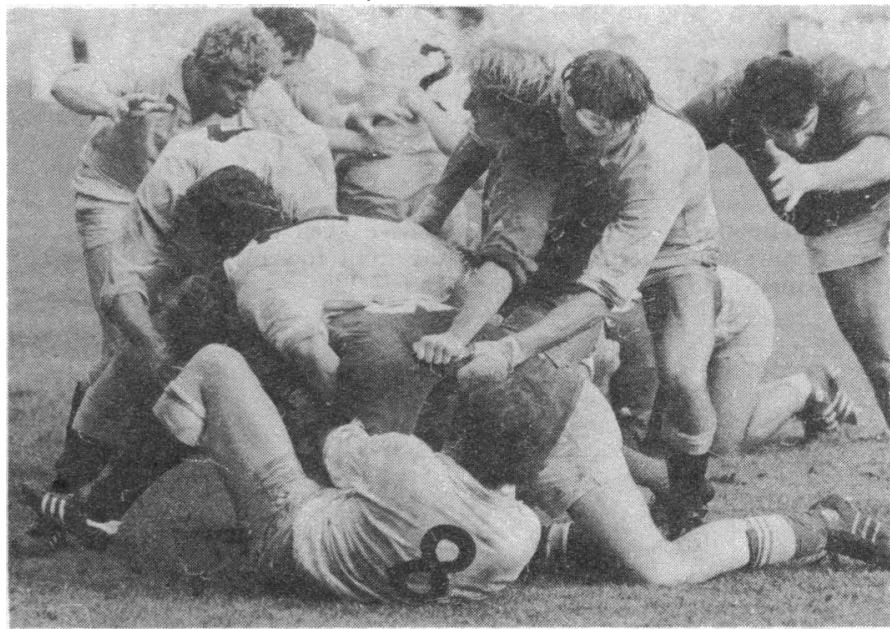

FIG 9-Rucks ând mauls can be extremely dangerous as players are wrestling and fighting for the ball on the ground. Here one player grapples with an opponent on the ground by placing his arm round his neck.

Late tackle, dropped on head

Strangled

Blow to neck

Kick to neck

Late high tackle

Someone left front row of scrum to fight; scrum collapsed

Straight arm tackle

Player was clotheslined (American football)

FIG 10-Analysis of injuries incurred through foul play. 
were playing with adults: they were unable to match them in strength, and so on three occasions the scrum collapsed. On another occasion a 15 year old boy turned up at the local club, played for the third team, and was pushed in the back while stooping for the ball. A 16 year old boy playing for a local club's second team broke his neck in a ruck and maul. The most vulnerable age for injuries appears to be 15 to 21 , but this may simply be because most players are in this age group.

\section{INCIDENCE OF INJURIES}

Table IV shows the incidence of injuries seen at the National Spinal Injuries Centre; at the spinal cord injuries centre, Conradie Hospital, Cape Town, South Africa ${ }^{6}$; and in New Zealand and Wales.

TABLE IV-Incidence of serious spinal injuries*

\begin{tabular}{|c|c|c|c|c|}
\hline Season & Stoke Mandeville & $\begin{array}{l}\text { Spinal cord injuries } \\
\text { centre, Conradie } \\
\text { Hospital, Cape Town, } \\
\text { South Africa }{ }^{6 \dagger}\end{array}$ & New Zealand ${ }^{15}$ & Wales" \\
\hline $\begin{array}{l}70-1 \\
71-2 \\
72-3 \\
73-4 \\
74-5 \\
75-6 \\
76-7 \\
77-8 \\
78-9 \\
79-80 \\
80-1 \\
81-2 \\
82-3\end{array}$ & $\begin{array}{l}1 \\
1 \\
1 \\
2 \\
3 \\
2 \\
3 \\
4 \\
8 \\
5 \\
9 \\
5 \\
3\end{array}$ & $\begin{array}{l}1 \\
1 \\
1 \\
1 \\
1 \\
4 \\
4 \\
4 \\
4 \\
8 \\
8 \\
7\end{array}$ & $\begin{array}{r}8 \\
6 \\
13 \\
1 \\
9 \\
17\end{array}$ & $\begin{array}{l}1 \\
3 \\
4 \\
1\end{array}$ \\
\hline
\end{tabular}

*Five schoolboys were injured in the United Kingdom during 1942-68, and 12 during 1973-8.16

tAmplified by details from Dr E Key (of Conradie Hospital; personal communication).

\section{Discussion}

Most of the players reported on here were treated by me at the Liverpool Regional Paraplegic Centre and the National Spinal Injuries Centre. As the mechanisms of injury and the causative factors seemed the most important information for my analysis, however, I obtained a few case histories from colleagues. I included the cases of injury sustained in rugby league and American football because the mechanisms of injury were similar. Only one patient had an injury outside the cervical spine, and that was due to a fall. The vulnerability of the lower cervical spine was obvious. Most injuries were caused by flexion, substantiating the views of Schneider ${ }^{17}$ and Bauze and Ardran. ${ }^{13}$ The only comparable study specifically of rugby injuries is one carried out in New Zealand of 54 cases that occurred from 1973 to 1978.15 Front row forwards were particularly at risk. Half of the forwards were injured in set scrums, and, as in this series, only one man who broke his neck in a set scrum was not a front row forward (he was a flanker).

Previous reports have drawn attention to the particular dangers associated with playing in the front row. ${ }^{4-7} 9-11$ With an eight man pack with a combined mass of $727 \mathrm{~kg}$ the force recorded on impact was $746 \mathrm{~kg}^{7}$ Other factors that cause injuries in the front row are accidental and deliberate collapsing of the scrum combined with continued pushing by the second row, charging so that the neck becomes extended, incorrect meshing, and discrepancies of strength and skill whereby weaker opponents can be pushed to the ground. Recognising these factors, the Rugby Football Union has since 1978-9 made various changes to the binding positions of the front row forwards, in particular of the tight head versus the loose head prop, the intention being to keep the scrum up and stop it from collapsing; players, referees, and coaches have accepted these changes. Gratifyingly, the number of injuries from these causes seen at Stoke Mandeville Hospital (one every two or three years) has hardly changed despite the increase in the overall number of injuries.
The number of injuries sustained in tackles has increased. In nearly all cases the tackler was injured because his technique was inadequate. Several of the players were schoolboys who were either not taught how to tackle at all and were unaware of the dangers of their head being incorrectly placed or were attempting to crash tackle, which is a dangerous manoeuvre specifically warned against in the coaching manuals. The high tackle that appears to be so dangerous caused only a minor instability in one of the American footballers and did not result in a complete cord transection; in an English schoolboy it caused a long period of unconsciousness with a moderate head injury and injury to the lips and mouth but did not result in a fractured spine.

A worrying aspect of this study is the injuries that occur to players carrying the ball. Many of these were caused by multiple tackles. The force generated in any accident is due to the rapidity of the deceleration. If a tackle is by a single player then both players will decelerate gradually as the player carrying the ball moves with the tackler, and the force will be dissipated in the movement of the shoulder of the player with the ball as he rotates on to his back. If several people tackle a player, however, his movements are restricted and the force cannot be dissipated by his body's moving away. This is a recognised technique in American football called "piling on," in which one man pushes another to the ground and partially holds him there while a subsequent tackler comes in and injures the man so severely that he is unable to continue the game. It would appear that this technique is being introduced into rugby union.

It is difficult to determine when the injury occurs in a tackle; several players described how they were tackled and then a maul and ruck developed, and it is not clear at what moment their necks became broken. Similar results were noted in the New Zealand series. ${ }^{15}$ The increase in the number of players injured in tackles seems to have occurred in recent years after a change in the laws. Until some 10 years ago a tackle was clearly defined: when a player could not do anything useful with the ball or when the ball touched the ground then a tackle had occurred and the ball had to be released and played with the foot. In an effort to speed up the game, however, playing the ball with the foot after a tackle was abolished, and then the definition of the tackle was changed so that the player could hold on to the ball and try to distribute it even when lying on the ground. This inevitably meant that other players would wrestle and fight for the ball and that the tackled player would hang on to it, leading to a maul and ruck.

The injuries sustained in the maul and ruck have increased dramatically. This is almost certainly due to the change in the tackle law and also to a change in the approach to the game. Rugby should be primarily a running and passing game. Unfortunately in recent years, particularly in the United Kingdom, players have developed the technique of taking the ball to the ground; other players drive in to try and play it with their foot and in sweeping the man with the ball aside often drive into him. This may be aggravated by poor technique: several players reported that, instead of going correctly into the maul and ruck with the ball tucked under one arm (so that when they fell to the ground they rolled on to their back and released the ball sideways), they went into the maul and ruck and tried to pass the ball out between their legs. In that position their head was locked to the ground so that they could not avoid injury to their neck by putting their arms up or taking the force on their shoulders; thus dislocation occurred and the cord was damaged when other players pushed on them.

The maul and ruck is treated differently in New Zealand and the United Kingdom. In the United Kingdom the players go to ground with the ball, the players themselves being out of play. In New Zealand the players put the ball to the ground but try to stay on their feet, thus remaining in play. Whichever technique is used, the maul and ruck is inevitably dangerous. Large powerful men wrestle with the ball, some trying to keep it in the hand and distribute it, others wrestling to put it 
on the ground. It is now illegal for defending players to "go over the top" of a maul to kill the ball once it is on the ground and so prevent it from becoming available. Rucks and mauls are a grey area in rugby laws and unless firmly controlled by the referee too easily provoke players to ill tempered violence.

An emotive question is, has the incidence of injuries increased ? Due to a change in the laws in 1969 whereby the direct kick into the touch outside 22 metres is no longer permitted and to the change in the tackle law the actual playing time is much longer. ${ }^{18}$ The exact number of people who play rugby and the number of games that they play are not known, and so the proportion of games in which serious injuries occur is not known. Nevertheless, the absolute number of patients admitted to units with broken necks sustained in rugby games indicates that more people are breaking their necks in such games. This is the case with figures from the Conradie Unit in South Africa ${ }^{6}$ (table IV), and from Wales ${ }^{8}$ and in schoolboys ${ }^{16}$; only in New Zealand are the figures equivocal. ${ }^{15}$

The purpose of this study was to determine the reason why players break their necks. Is it due to lack of technique? Are less skilled players more likely to break their necks than skilled ones? My findings suggest that greater skill does not protect, as six of the players injured were first class players and there are only about 2000 such players in England compared with a total of 400000 players at all standards. The large number of injuries sustained on a recent tour by the England team (the Lions) supports the view that the stronger and fitter the player the greater the likelihood of an injury occurring. Schneider ${ }^{17}$ made a separate study of this among American players. He found that 141 serious injuries occurred among 780000 highschool football players, 34 among 70000 university footballers, and 14 among 4500 professional players; whereas in Sandlot football, an unskilled form of the game, 26 injuries occurred among 1645000 players. He concluded that unskilled players do not play as hard as highly skilled or professional athletes and that the greater degree of force and skill exaggerates the likelihood of injury. Injuries among schoolboys in this study lend support to this view. Sixteen of the schoolboys injured were team players, compared with four non-team players; most of the injuries occurred in competitive games. Again it is impossible to establish the total numbers of team and non-team players in schools, but in two public schools the ratio of team players to non-team players was $1: 3$.

Lack of fitness, lack of skill, and a mismatch of strength have all been emphasised in the past as factors causing injury. Mismatch of strength and skill is most likely to be apparent in the front row, when a more powerful opponent can pull or push down a weaker player. The mixing of boys with adults, with players weighing 18 stone $(114 \mathrm{~kg}$ ) playing with boys weighing 9 stone $(57 \mathrm{~kg})$, used to occur fairly often as there was an anomaly whereby boys of 16 and over who had left school could play with adults but schoolboys of 16 and over could not. As a result of representations 111920 accepted by the Rugby Football Union ${ }^{21}$ schoolboys are no longer able to play with adults in club games and the annual fixtures between schoolboys and "old boys" have been stopped except purely for training purposes under the supervision of the rugby,master. Problems can occur at schoolboy level as although it is desirable to match players by weight, as is done in New Zealand, this is extremely difficult in England because the games are organised at school rather than club level and, particularly around the age of puberty, large discrepancies of weight and strength occur in boys of the same age.

Eleven players were injured as a result of foul play. Two players deliberately had their necks broken. These deplorable figures are substantiated by a larger study by Davis and Gibson, who found that $12-31 \%$ of all rugby injuries were the results of illegal play and that in half of these cases no penalty kick was awarded. ${ }^{22}$ When an injury has occurred as a result of illegal play the injured player may sue for damages in the civil courts; success is more likely if a penalty kick was awarded. If a referee observes some illegal play but incorrectly allows the advantage law to stand then not only will the injured player have difficulty in recovering damages but the player who was responsible for the injury is likely to carry on perpetrating such illegal play.

As a result of all these injuries attention has been drawn to the inadequacy of insurance cover. A club that is affiliated to the Rugby Football Union has to carry insurance cover, but the units are far too small: a compulsory minimum of only three units has to be purchased, which would yield, to someone who is permanently disabled, only $£ 8100$. The Rugby Football Union in 1983 urged clubs to purchase more units to yield a realistic cover. ${ }^{23}$ The cost is only $£ 16.50$ for three units per team per season. When I began this study I found that schools do not have to carry insurance. Largely as a result of representations made in the past, fee paying schools are now taking out adequate insurance, but state schools are still not covered. 1119

There is an almost total lack of any statistical information on the distribution, nature, and cause of the injuries. Obtaining the histories presented here took many hours of interviews with the players, their coaches, and their team mates. Most players have no ideas of the risks and techniques of the game, and the injured players thought that the way in which they were injured was just bad luck. The International Rugby Football Union has set up two scholarships to obtain accurate information about injuries on which firm conclusions can be based; one of these scholarships is already being implemented in Wales.

The findings presented here were first presented in 1975 in Dublin $^{10}$ and subsequently to the British Medical fournal ${ }^{11}$ and members of the Medical Officers of Schools Association. ${ }^{18}$ Some of my points have been taken up by the Rugby Football Union, ${ }^{21}$ particularly the risks of lack of experience, that teams should be matched for strength and age, and that the spirit of the game is ill served by "psyching players up." The Rugby Football Union cannot change the laws of the game; that takes many years and must be done by the international board. Recognising the dangers emanating from the scrummage, maul, and tackle, however, the union made recommendations, supported by New Zealand, which led to a change in the laws within the past few years. The emphasis is to keep players on their feet and to avoid pile ups, and in the scrum to prevent collapsing.

After a joint meeting of doctors, rugby players, and administrators in 1983 at which I presented my findings, ${ }^{24}$ the Rugby Football Union set up a committee, to which I was the chief witness. Within four months it produced a series of changes in interpretations of the laws for schools, supported by instructional pamphlets to make the game safer. ${ }^{25}$ The pamphlets advise that the shoulders should not dip below waist height in the scrummage and that players should remain on their feet, tackle correctly, adopt the correct attitude towards the game, and train for specific positions. The Rugby Football Union has tried hard to eliminate injuries and has worked in the closest collaboration with the Medical Officers of Schools Association. I hope no schoolboy ever has to write as one did in 1979:

"Since I have been here there have been five rugby accident patients in this ward, four of whom were injured while playing schoolboy rugby. I am the only one of these four who will ever walk again or, in fact, have any sensation from the ribs downwards. Also the other three will never have the full use of their hands; two have one or two fingers back and one has nothing at all. The fifth accident can move nothing from his neck downwards. I am very lucky indeed. With the height of my break I should either be dead or totally paralysed. There have been twice as many spinal rugby injuries this year so far as there were last year.

"What I am asking is that my school, as a highly influential rugby school with a very influential staff, should look into the game and try to stop these accidents which stem from the scrum and the maul, since, next time, whoever gets hurt may not have the extraordinary good fortune that I have had. Having just watched the England/ Scotland centenary match I have noticed the extremely high level of competitive play which has spread down to schoolboy level, in which the physical capabilities of the 16 to 18 year olds cannot match those 
of fully grown adults. This type of highly competitive play can be watched every week on Rugby Special and Grandstand and has, inevitably, influenced schoolboy play. Any signs of this happening should be stamped out with some vigour as has happened with neck tackling, which is now more or less eliminated.

"This competition which I have mentioned is becoming more apparent as my school has an unbeaten record for four years and next year the pressure will be even greater to 'get' my school. I am not for one moment suggesting that the school steps down and plays like a load of fairies, but that an effort is made to control the obvious aggression which, at the moment, remains within the legal bounds of the game. A lot of damage is done when a maul collapses and a ruck is left too long in which players push over the top and fall in a heap, giving those underneath no time to think about falling correctly. These accidents that happen are not generally the result of open aggression but are frequently the result of very intense competition which is spreading from the 'professional contest' at international level down into the adolescent game in which broken limbs and possibly worse are a high price to pay for some fun."

I thank Mr Kevin Silver for his painstaking analysis of the results; Mr Ian Beer, headmaster of Harrow School and chairman of the rules subcommittee of the Rugby Football Union, and Mr Don Rutherford, technical adviser to the Rugby Football Union, for reading the manuscript and giving constructive criticism of the text; my colleagues at the National Spinal Injuries Centre, Stoke Mandeville Hospital-Dr J J Walsh, Dr H L Frankel, Mr I Nuseibeh, and Mr D O Hancock-for allowing me to study their patients; Mr P H Osterburg, Dr B Francis-Jones, Mr T McSweeney, Mr R Sutton, and $\mathrm{Mr} B$ Cashman for sending me details of patients under their care; and Mrs Lindsay Frankland for carefully assembling and typing the manuscript.

All photographs are by Colorsport.

\section{References}

1. Sparks JP. Half a million hours of rugby football-the injuries. $\mathrm{Br} \mathcal{F}$ Sports Med $1981 ; 15: 30-2$.

${ }^{2}$ Myers PT. Injuries presenting from rugby union football. Med $\mathcal{f}$ Aust $1980 ; 2: 17-20$

${ }^{3}$ Reilly T, Hardiker R. Somatotype and injuries in adult student rugby football. 7 Sports Med Phys Fitness $1981 ; 21$ :186-91.
4 Scher AT. Rugby injuries to the cervical spinal cord. $S$ Afr Med $\mathcal{F} 1977$; $51: 473-5$.

5 Scher AT. Rugby injuries to the cervical spinal cord. S Afr Med $\mathcal{f} 1980$; $57: 37$.

- Scher AT. Vertex impact and cervical dislocation in rugby players. $S$ Afr Med $\mathcal{F} 1981 ; 59: 227-8$.

"Scher AT. "Crashing" the rugby scrum-an avoidable cause of cervical spinal injury. $S$ Afr Med f 1982;61:919-20.

${ }^{8}$ Williams JPR, McKibbin B. Cervical spine injuries in rugby union football. Br Med f 1978;ii :23-30.

9 Silver JR. Neck injuries: the constant threat to rugger players. General Practitioner 1972;September 1:10-1.

10 Silver JR: Rugby' injuries of the spine. In: O'Connell TCJ, ed. Injuries in rugby football and other team sports. Dublin: Irish Rugby Football Union, 1975:110-5.

11 Silver JR. Rugby injuries to the cervical cord. Br Med F 1979; i:192-3.

12 Roaf R. A study of the mechanics of spinal injuries. $\mathcal{F}$ Bone foint Surg $1960 ; 42 B: 810-23$.

13 Bauze RJ, Ardran GM. Experimental production of forward dislocation in the human cervical spine. $\mathcal{A}$ Bone foint Surg 1978;60B :239-45.

14 Braakman - R, Penning L. Injuries of the cervical spine. Amsterdam: Excerpta Medica, $1971: 168-9$.

15 Burry HC, Gowland H. Cervical injury in rugby football-a New Zealand survey. Br $\mathcal{F}$ Sports Med 1981;15:56-9.

${ }^{16}$ Hoskins T. Rugby injuries to the cervical spine in English schoolboys. The Practitioner 1979 ;223:365-6.

17 Schneider RC. Head and neck injuries in football: mechanisms, treatment, and prevention. Baltimore: Williams and Wilkins, 1973.

${ }^{18}$ Rugby Football Union. Fitness training for rugby. Twickenham, Middlesex: Rugby Football Union, 1978.

19 Kinkade J. Rugby football injuries to the cervical cord. Chandos Street, London W1: Medical Officers of Schools Association, 1979. (Letter to headmasters of public schools in Northern Ireland.)

${ }^{20}$ Silver J, Davies JE, Walkden L, Moffat R, Hoskins T. Letter to public schools. Chandos Street, London W1: Medical Officers of Schools Association, May 1979.

${ }^{21}$ Harrison DH, Walkden L, Moffat R, Kendall-Carpenter J, Weighill RHG. Rugby injuries in schools. Twickenham, Middlesex: Rugby Football Union, July 1980 . (Letter to all schools.)

${ }^{22}$ Davies JE, Gibson T. Injuries in rugby union football. $\mathrm{Br}$ Med f 1978; ii : $1759-61$.

${ }^{23}$ Weighill RHG. Death and total disability accident insurance scheme. Twickenham, Middlesex: Rugby Football Union, 1983.

${ }^{24}$ Anonymous. Rugby football injuries meeting. Family Magazine (AMI Hospitals Ltd) 1983;4:5.

${ }^{25}$ Rugby Football Union. Injury prevention 1, 2, 3, and 4. Twickenham, Middlesex: Rugby Football Union, 1983.

(Accebted 17 October 1983)

\section{Venice observed}

An exhibition recently opened at the Royal Academy of Arts is aptly entitled "The Genius of Venice, 1500-1600.". Venetian artistic genius of the cinquecento is richly represented. There are also several incidental insights of medical interest.

During the Renaissance physicians became socially important. Some portraits of physicians are included in the exhibition, two of them painted by Titian. The professional identity of one of the sitters has, however, been a matter of debate. On the window sill behind the subject of the portrait is either a medicine box or a paint box. Both pigments and drugs could be obtained from an apothecary, but whether the box had been supplied to an artist or to a doctor has not been settled.

Among small bronzes by Riccio of Padua, lent by the Louvre, are two bas reliefs, "The Illness of the Professor" and "The Soul of the Professor in the Fortunate Woods." They represent part of the funerary monument to Della Torre senior, a worthy physician, as well as to one of his sons, Marco Antonio della Torre, professor of medicine in Padua. The latter, according to Vasari, "was among the first to cast a real light on anatomy, which up to that time had existed in the deepest shadows of ignorance; and in this he was marvellously served by the genius, work and hand of Leonardo da Vinci ..." In the catalogue to the exhibition is an intriguing discussion of the reliefs and their entirely pagan character.

During this century of artistic achievement outbreaks of the Black Death were common. St Christopher, St Roch, and St Sebastian were all invoked against the plague-in a painting by Lotto, St Roch points to a fearsome bubo in his groin. In another painting St Pantolon is shown healing a child who has some other affliction: a rather charming looking miniature devil is depicted scuttling away from the possessed boy; the medicine box held by an assistant goes unused and the helplessness of Asclepius in the face of such a miracle is symbolised by a statue without arms and legs. Such were the contemporary powers of alternative medicine.-DENIS GIBBS, London.

How much fat is removed from milk in the process of skimming: is the removal total?

The efficiency with which fat is removed from milk by skimming can be controlled, and it is possible to produce a series of partially skimmed milks with fat contents that are progressively reduced compared with whole milk. The total removal of fat is technically exacting, and skimmed milk therefore has a little residual fat, which may be as low as $0.1 \%$ (which implies that only 3\% of the fat originally present in whole milk remains). ${ }^{1}$ The legal maximum for liquid skimmed milk is $0.3 \%$ and "semi-skimmed milk" must contain between $1.5 \%$ and $1.8 \%$ fat. ${ }^{2}$ D A T SOUTHGate, head, nutrition and food quality division, Food Research Institute, Norwich.

' Paul AA, Southgate DAT. McCance and Widdowson's the composition of foods. - Drinking milk regulations, 1977. (SSI 1977, No 1866.) 